Review Article

\title{
Anti-Diabetic Property of Catharanthus roseus leaves and Psidium guajava Leaves
}

\author{
Kirti Chauhan', Srishti Negi $i^{2}$
}

${ }^{1}$ M.Sc. Student, ${ }^{2}$ Assistant Professor, Department of Nutrition and Dietetics, Manav Rachna International Institute of Research and Studies, Manav Rachna International University, Faridabad, India.

DOI: https://doi.org/10.24321/2394.6547.202001

I $\quad \begin{array}{lllll}\mathbf{N} & \mathbf{F} & \mathbf{O}\end{array}$

Corresponding Author:

Kirti Chauhan, Department of Nutrition and Dietetics, Manav Rachna International Institute of Research and Studies, Manav Rachna International University, Faridabad, India.

E-mail Id:

kirtichauhan02@gmail.com

Orcid Id:

https://orcid.org/0000-0002-8945-6420

How to cite this article:

Chauhan K, Negi S. Anti-Diabetic Property of Catharanthus roseus leaves and Psidium guajava Leaves. J Adv Res Ayur Yoga Unani Sidd Homeo 2020; 7(1\&2): 1-5.

Date of Submission: 2020-05-27

Date of Acceptance: 2020-06-23
$\begin{array}{llllllll}\mathbf{A} & \mathbf{B} & \mathbf{S} & \mathbf{T} & \mathbf{R} & \mathbf{A} & \mathbf{C} & \mathbf{T}\end{array}$

Background: Sadabahar (Catharanthus roseus) termed as periwinkle all over India, belongs to 'Apocynaceae' family, and is an evergreen everblooming bushy herb in tropical parts of the world like India, America, Australia and Malaysia. The leaves consist of alkaloids like vincristine and vinblastine that provide medicinal benefits like anti-diabetic, anti-cancer and anti-microbial traits. Guava (Psidium guajava) is a fruit consumed in various countries, harvested in tropical and subtropical areas. It is an evergreen tree, belongs to Myrtaceae family. Guava leaves are rich in flavonoids, carotenoids, aldehydes, tannins and vitamin C. The leaves are effective in management of diabetes and obesity. Diabetes mellitus is a metabolic disorder caused by changes in carbohydrate, protein, and fat metabolism, expressed with high sugar or glucose levels in the blood. The disease for prolonged period of time leads to retinopathy, high blood pressure and cardiovascular disease.

Aim: To study the health benefits of Sadabahar and guava leaves for diabetic patients.

Methods: Research papers related to the benefits of Sadabahar and guava leaves are studied and the finding of each article reviewed.

Result and Conclusion: The diabetic patients must include dried Sadabahar and Guava leaves powder regularly in their daily dietary routine, as the use of herbal products in treating diabetes is increasing day by day because of no side effects. Therefore, there is an increased need for product development using Sadabahar and guava leaves for diabetes.

Keywords: Catharanthus roseus, Alkaloids, Psidium guajava, Diabetes Mellitus

\section{Introduction}

Diabetes or diabetes mellitus (DM), is a metabolic disorder that results in a higher glucose level in the blood. ${ }^{1}$ Hyperglycemia either occurs from the defects in pancreas for insufficient production of insulin or in the insulin work in the body or shall be both, i.e., it may be insulin dependent or non-insulin dependent. ${ }^{2}$

\section{Types of Diabetes}

This disorder is divided and elaborated in the two categories 
that is type 1 and type 2 diabetes mellitus. The diabetes in which the patient is dependent on insulin is called type $1 \mathrm{DM}$; in this case, the pancreas of the patient did not produce insulin in this case and the diabetes in which there is no need of insulin is called as type 2 diabetes; i.e., in this case, the insulin is formed by the pancreas but its action is not fully functional due to various factors. Some of them may have obesity and insulin resistance, etc. ${ }^{3}$

The hyperglycemic condition of any person if not treated till long time then such people show prolonged effects of this disease in their body like the development of retinopathy, cardiovascular disease, etc. However, these effects are sometimes severe and sometimes not, depending upon the time period of suffering from this problem and also upon the type of diabetes mellitus. In current scenario, it is very normal in children to be a diabetic and due to insulin deficiency, symptoms such as weight loss, polyuria, blurred vision, and polydipsia occur in children. Death may also happen due to uncontrolled diabetes. ${ }^{4}$

Diabetes also leads to variation in fat, protein and carbohydrate metabolism. The use of herbal plants with anti-diabetic property is very popular around the world. The demand of using plants which has medicinal effects is higher these days as such plants have natural ability to treat diseases and also there are not any side effects of using natural products in case of diseased condition as compared to the medicines that are not natural and are not plant based but is prepared from chemicals and thus cannot be used for the longer period of time. There are many plants that have anti-diabetic property in Ayurveda science. ${ }^{5,6}$

\section{Prevalence}

The prevalence of diabetes is increasing very rapidly throughout the world, mostly in the middle-income countries. Every year the new cases of hyperglycemia that are diagnosed are more than 79000 . Mostly adults of 15 years to 20 years of age are more prone towards type 1 diabetics in America. The cases of type 1 condition are more in the United States as compared to the other countries in the world. Even, in the world, type 1 hyperglycemic patients is not much popular as there are less cases in such situation is known. The prevalence of type 2 diabetes-mellitus is more than that of type $1 \mathrm{DM}$; so, the people from 20 to 79 years of age and above mostly have this type 2 disease. Also, $90 \%$ of the people suffering from high blood sugar levels belong to this category only. ${ }^{4}$

The $3 \%$ of the total population in the world is dealing from diabetes and by the year 2025 it shall be doubled. ${ }^{7}$ The number of people will be 37 million by 2030 with diabetic disorder. $^{3}$

Asia is considered as the center of the disease, i.e., diabetes, as more than $60 \%$ of people suffering from this disorder are in Asia which contributes to the global load of patients dealing with this problem. Among the two types of diabetes mellitus, the type $2 \mathrm{DM}$ is very common that occurs in most cases. In India, there are around 69.2 million people who are dealing with type 2 diabetes and India is the second highest country next after the China in the world with the people suffering from type-2 DM. The number of patients is raising very rapidly in India suffering from the disease and within the coming five years India will turn into the world's first country with the maximum number of people living with hyperglycemia globally. ${ }^{8}$

\section{Catharanthus roseus}

Catharanthus roseus is also known with other various names which are periwinkle, old maid and Vinca rosea. It is also named as evergreen ever blooming plant. It is pronounced by the name of Sadabahar in Hindi. It is believed that this plant was brought to India in the $18^{\text {th }}$ century, by the Portuguese mercenaries in the state Goa. This is the most studied and researched plant by a number of researchers. It is an evergreen, bushy herb. The leaves are formed in opposite pairs with a pale midrib and glossy green color in appearance. ${ }^{9}$ The shape of leaves is oval to oblong, that are 1 to $3.5 \mathrm{~cm}$. broad and 2.5 to $9.0 \mathrm{~cm}$ long. ${ }^{10}$

The plant is native to and was first evaluated in the Indian Ocean island of Madagascar and is widely cultivated and is naturalized in tropical parts of the world like India, America, Australia, china and Malaysia. ${ }^{11}$

It consists of more than 100 alkaloids. It is also identified as one of the 21000 natural medicinal importance plants. Different parts of the plant contain contrasting various alkaloids which are produced in different numbers. Its most interesting and important property is its conventional use in the treatment of diabetes. ${ }^{10}$

Different alkaloids present in Vinca rosea possess different medicinal effects against various diseased conditions, from which some alkaloids act as anti-hyperglycemic (bring down the glucose level of the body), some of them work like antioxidant for cells and anti-microbial effects, whereas some help in lowering down the blood pressure and some help in providing the treatment of cancer, etc. However, leaves perform action of anti-cancer drug therapy also. Vincristine and vinblastine are the two important alkaloids that have been isolated and extracted from the plant due to their anti-cancer properties. ${ }^{6}$

\section{Nutritional composition of Catharanthus roseus leaves}

Sadabahar leaves consist of various nutrients and some amount of anti-nutrients. The minerals that are present in the leaves are calcium, iron, sodium, phosphorus and potassium. Vitamin Cis also present in the leaves but in little 
amount, i.e., $0.08 \mathrm{mg} / 100 \mathrm{~g}$. It acts as an antioxidant in the body. Moisture content of the leaves is very high, i.e., $84 \%$ which therefore reduces its shelf life. Crude protein, crude fiber, crude lipid and carbohydrate are also present in the leaves. The amount of ash content of the leaves is $3.89 \% .^{12}$

Some amount of anti-nutrients is also present in the leaves, which includes total oxalates, soluble oxalates, phytates and tannins. Alkaloids are also present in the leaves. The anti-diabetic activity of the leaves is because of the alkaloids present in the leaves. As, the substances like tannins, phytates which are antinutrients present in Vinca rosea leaves may work against the dangerous effects of diabetes mellitus by acting as antioxidant in the body through calming free radical effects. ${ }^{12}$

\section{Health Benefits}

The ancient Indian system to cure diseases is Ayurveda that focuses on the medicinal properties of plants. Vinca rosea is the plant that is studied and well recognized by Ayurvedic sciences. This plant has been well known for its various medically beneficial properties that can be useful for disease people; it belongs to Apocynaceae family and is used to prevent many disease conditions naturally. ${ }^{13}$

\section{- Anti-diabetic}

The Sadabahar leaves possess anti-diabetic activity as the leaves extract has been proven to decrease blood glucose levels on a dose dependent basis in many studies as compared to the standard drug (glibenclamide). The anti-diabetic effect is due to the alkaloids packed in the leaves which increases insulin production; cells of pancreas are repaired and side by side glucose usage in the liver is enhanced..$^{14}$

The anti-hyperglycemic activity of the leaves is due to their action on liver as the leaves increase the utilization of glucose in the liver. The alkaloid present in the leaves which possess anti-diabetic effect is named as vinculin which has been isolated from the leaves of the plant and is studied pharmacologically and is marketed for use in diabetes treatment. ${ }^{14}$

\section{- Anti-cancer}

There are two alkaloids namely vincristine and vinblastine that are found to be there in the leaves of Sadabahar, and the anti-cancer action of the leaves is due to the presence of these two alkaloids only. Out of which, vincristine is effectual and is used in the treatment of leukemia in the children and is sold with the name of oncovin in the market. Whereas vinblastine is used for neoplasms and specified for Hodgkin disease and is available with the name of velban. ${ }^{6}$

\section{- Anti-microbial}

The old maid leaves possess anti-microbial outcome against various microorganisms such as Salmonella typhimuruim, Pseudomonas aeruginosa and Staphylococcus aureus, etc. The leaves can be used in long-term wounds cleaning and to treat numerous diseases. ${ }^{10}$

\section{- Anti-oxidant}

The extract of periwinkle leaves shows anti-oxidant activity as alkaloids, vitamin C content, tannins in the leaves acts as antioxidant against the free radicals in the body. ${ }^{15}$

\section{- Hypotensive activity}

The methanolic extract of the leaves of Vinca possesses hypotensive effects, which is proven in many research studies. The hypotensive activity is due to the content of various active substances and alkaloids. ${ }^{10}$

\section{Psidium guajava}

Psidium guajava is commonly called as guava. Guava is the fruit that is commonly ingested in India and other parts of the world. It is the shrub from Psidium genus. It belongs to the Myrtaceae family. It is an evergreen tree. Guava trees are native to tropical countries. The color of the Guava leaves is dull green. ${ }^{16}$

The word guava is derived from Arawak guayabo, through the Spanish word guayaba. Generally, the guava fruit is eaten in the raw form, its juice is also prepared industrially and is consumed by many people. Jellies and jams are also prepared from the guajava and consumed. The skin of the fruit is green to yellow in color with white or yellowish flesh. ${ }^{17}$

This plant has various medicinal advantages besides providing the nutrients to the body. It has been used since from very long time in the Ayurveda and conventionally across the world in treating various diseases. The whole plant including its all parts has been used for treating varied disease conditions. Its roots, leaves, fruit and bark is commonly used in treating gastric disorder such as diarrhea, stomachache etc. in various countries. Its leaves are proven to be successful in treating diabetes mellitus, by bringing high glucose levels in the blood down near to the normal and therefore possess anti-diabetic activity. The seeds and pulp of its fruit are normally being used in providing relief from gastrointestinal disorders, respiratory disorders, act as anti-inflammatory and lower down high blood pressure. ${ }^{3}$

\section{Nutritional Composition of Psidium guajava Leaves}

There are certain minerals and other nutrients present in the leaves which provide body with the nutritional benefits and help in meeting the requirement of the body's nutrients. Along with the nutritional needs, the leaves provide various medicinal advantages also.

The guava leaves contain high amount of moisture, i.e., $82 \%$ 
to $83 \%$. The macronutrients which are present in the leaves are carbohydrate, protein, and lipid. The amount of protein present is $18.5 \mathrm{~g}$, carbohydrate is $20 \mathrm{~g}$ to $21 \mathrm{~g}$. Vitamin C is also present in the leaves in the amount $12.5 \mathrm{mg} .{ }^{18}$

Certain minerals are also present in the leaves such as iron, calcium, phosphorus, and potassium. There is little amount of ash also present in the leaves. Fiber is also present in the leaves. The damaged leaves and infected leaves can be observed as by the light or dark brown spots on the leaves, or by the holes in the leaves or either by changes in color from green to dark brown color. ${ }^{18}$

In the phytochemical analysis of the leaves it is found that, there are alkaloids, triterpenes, carotenoids, vitamin $C$, anthocyanins, flavonoids, quercetin, essential oils and aldehydes are present in the leaves. ${ }^{1}$

\section{Health Benefits}

Guava leaves possess medicinal properties and thus have been used to treat various diseases. It is used as the medicinal tree because all parts of this plant are used to treat different disease conditions. The leaves possess antimicrobial, anti-inflammatory, anti-diabetic, anti-allergic, anti-hypertensive and anti-cancer and the like properties. Its leaves, fruit, roots and bark are beneficial and give relief in diarrhea and stomachache. Leaves are used in the treatment of gastrointestinal disorder, respiratory disorders, anti-diabetic activity and help in controlling hypertension too. ${ }^{3}$

\section{- Anti-diabetic}

Guava leaf extract possesses anti-diabetic property and this effect happens due to the prohibited activity of the enzyme alpha-glucosidase (alpha-amylase, maltase) due to which carbohydrates in the body are not digested; as a result, glucose is not formed from carbohydrate after its digestion and glucose levels in the blood do not get raised. And also, it repairs pancreatic beta cells when particular amount of appropriate dose is given. Thus, it prevents increase in blood sugar levels. ${ }^{19}$

\section{- Anti-hyperlipidemic activity}

Guava leaves show anti-hyperlipidemic activity due to the presence of active components in the leaves such as flavonoids, polyphenols, esters, carotenoids, etc. ${ }^{19,3}$

\section{- Anti-cancer}

The leaves possess anticarcinogenic consequence. The active components of the leaves perform like an antioxidant and protect the body's cells from getting damaged against the harmful carcinogens in the body. ${ }^{3}$

\section{- Anti-inflammatory}

The whole guava fruit and its leaves possess antiinflammatory and antispasmodic properties. Also, the leaves prevent the inflammation of respiratory system, gastrointestinal and other organs of the body. It may be due to the presence of vitamin $\mathrm{C}$, flavonoids and other compounds in the leaves. ${ }^{3}$

\section{- Gastro-intestinal disorder}

The leaves of guajava, its whole fruit and seeds are very beneficial in the control of gastrointestinal disorders, as they promote good digestion, possess anti-diarrheal activity, are beneficial in treating and providing comfort in stomachache, etc. ${ }^{3}$

\section{- Anti-oxidant}

The leaves contains vitamin $\mathrm{C}$ and other compounds such as flavonoids, etc., which act as antioxidant and help in protecting the body's cells from harmful free radical effects, thereby the leaves possesses antioxidant activity. Due to diabetes, the formation of free radicals in the body increases which increases the oxidative stress in body. So, the antioxidant compounds present in the leaves and the leaf extract help in preventing and protecting the body's cells from such oxidative stress also. ${ }^{1}$

\section{Conclusion}

The above study shows that Catharanthus roseus leaves are rich in alkaloids and tannins whereas Psidium guajava leaves are rich in aldehydes, carotenoids, alkaloids, tannins, etc. These compounds in the leaves possess anti-diabetic property, along with several other therapeutic benefits. As both these leaves are natural, therefore don't have any side effects. So they can be used by the diabetic patients. As there is not any exact drug for diabetes and medicine used for this has side effects, thus cannot be used for a longer time period. Therefore, there is an increasing need for product development research using these leaves for diabetic patients, so that the products shall be made as well as be easily available in the market to help diabetic people manage blood glucose levels.

\section{Sources of Funding}

I have not received any financial support for the research, authorship or publication of the Article.

\section{Ethical Approval: N/A \\ Conflicts of Interest: None \\ References}

1. Jayachandran M, Vinayagam R, Ambati RR, Xu B, Man Chung SS. Guava Leaf Extract Diminishes Hyperglycemia and Oxidative Stress, Prevent $\beta$ - Cell Death, Inhibits Inflammation, and Regulates NF-kB Signaling Pathway in STZ Induced Diabetic Rats. BioMed Research International Volume 2018; Article ID 4601649.

2. Bahrani AHM, Zaheri H, Soltani N, Kharazmi F, Keshavarz $M$, Kamalinajad M. Effect of the Administration of 
Psidium guava Leaves on blood glucose, lipid profiles and sensitivity of the vascular mesenteric bed to Phenylephrine in streptozotocin- induces diabetic rats. Journal of Diabetes Mellitus 2012.

3. Musdja MY, Mahendra F, Musir A. Anti-hyperglycaemic effect and glucose tolerance of guajava (Psidium guajava L.) leaf ethanol extract in diabetic rats. IOP Conference Series: Earth and Environmental Science 101 (2017) 012006.

4. Kharroubi A, Darwish HM. Diabetes mellitus: The epidemic of the century. World journal of diabetes 2015.

5. Vega-Avila E, Cano- Velasco JL, Alarcon-Aguilar FJ, del Carmen Fajardo Ortiz M, Almanza-Perez JC, Roman-Ramos R. Hypoglycemic Activity of Aqueous Extracts from Catharanthus roseus. Evidence - Based Complementary and Alternative Medicine Volume 2012; Article ID 934258.

6. Ahmed MF, Kazim SM, Ghori SS, Mehjabeen SS, Ahmed SR, Ali SM, Ibrahim M. Antidiabetic activity of Vinca rosea Extracts in Alloxan-induced diabetic rats. International Journal of Endocrinology 2010; Article ID 841090.

7. Basha SK, Kumari VS. In Vitro antidiabetic activity of psidium guajava leaves extracts. Asian Pacific Journal of Tropical Disease 2012.

8. Vijayakumar G, Manghat S, Vijayakumar R, Simon L, Scaria LM, Vijayakumar A et al. Incidence of type 2 diabetes mellitus and prediabetes in Kerala, India: results from a 10-year prospective cohort. BMC Public Health 19, Article number:140 (2019).

9. Kaushik S, Tomar RS, Gupta M, Mishra RK. An overview of Catharanthus roseus and medicinal properties of their metabolites against important diseases. European Academic Research 2017.

10. Mishra JN, Verma NK. A brief study on Catharanthus roseus: A review. International Journal of Research in Pharmacy and Pharmaceutical Sciences 2017; 2.

11. Nammi S, Boini KM, Lodagala SD, Behara RBS. The juice of fresh leaves of Catharanthus roseus Linn. Reduces blood glucose in normal and alloxan diabetic rabbits. BMC diabetic rabbits. BMC Complementary and Alternative Medicine 2003; article 4 [PubMed].

12. Choudhary S, Bisla G, Chaudhary J. Proximate nutrient composition and antinutrient analysis of Catharanthus roseus (Sadabahar) leaves explore their hypoglycemic potential. Corpus ID: 54783174, 2014.

13. Thounaojam MC, Nammi S, Jadeja R. Natural Products for the Treatment of Obesity. Metabolic Syndrome and Type 2 Diabetes 2016; Article ID 9072345.

14. Mishra JN, Verma NK. A brief study on Catharanthus roseus: A review. International Journal of Research in Pharmacy and Pharmaceutical Sciences 2017; 2.
15. Tiong SH, Looi CY, Hazni H, Arya A, Paydar MJ, Wong WF et al. Antidiabetic and Antioxidant Properties of Alkaloids from Catharanthus rpseus (L.) G.Don. Molecules 2013.

16. Uzzaman S, Akanda KM, Mehjabin S, Parveez GMM. A short review on a Nutritional Fruit: Guava, Open Access: Toxicology \& Research, 2018.

17. Joseph B, Priya M. Phytochemical and Biopharmaceutical Aspects of Psidium guajava (L.) Essential Oil: A Review. Research Journal of Medicinal Plant 2011.

18. Chuku E. Proximate Composition of Guava Leaves (Psidium Guajava L) and Associated Field Fungi. Nigerian Journal of Mycology 2009.

19. Deguchi Y, Miyazaki K. Anti-hyperglycemic and antihyperlipidemic effects of guava leaf extract. Nutrition \& Metabolism 2010. 